\title{
Notas para un estudio de la evolución de la judicatura
}

Felipe Westermeyer Hernández Estudiante de Derecho, Universidad de Chile

\section{Introducción}

Hay consenso entre los historiadores en que el proceso de emancipación implicó ruptura y continuidad a la vez, así como la completa recepción de las ideas de vanguardia del siglo XVIII, que ya estaban presentes en Chile desde fecha no próxima ${ }^{1}$. Este proceso también se refleja en la evolución de la judicatura chilena en la segunda mitad del siglo XVIII y la primera de la centuria siguiente ${ }^{2}$.

La judicatura es una de las instituciones de mayor historia y tradición en Chile. Junto con la iglesia, el ejército, el parlamento, el cabildo y la municipalidad, el presidente de la república y la Universidad de Chile -incluyendo en ésta las instituciones que la preceden y que se remontan hasta el siglo XVII- forman el núcleo de instituciones que han consolidado el estado de derecho y la tradición jurídica existente en el país. Estas son las instituciones matrices que han encauzado gran parte de los conflictos y procesos de cambio de que da cuenta nuestra historia y que han propugnado por una solución acorde con el estado de derecho.

Lo anterior no significa, sin embargo, que la relación entre estas instituciones haya sido pacífica. Sería anormal en la vida de un pueblo que ello ocurriera. Lo importante es que pese a las tensiones que origina la relación entre estos institutos exista una solución conforme a la legalidad, el diálogo y la voluntad de la mayoría con un respeto por los derechos de la minoría; por ende, el estado de derecho en Chile sólo se ha quebrantado en las ocasiones en que alguna de las recién mentadas instituciones ha suprimido o invadido completamente las atribuciones de otra ${ }^{3}$.

En este contexto la judicatura cumple una labor esencial. El hombre por naturaleza es un ser social y por ser las capacidades y recursos de los que está dotado escasos, es imposible satisfacer completamente las necesidades que emanan de su individualidad. Por ello, el con-

Al respecto, véase Barros Arana, Hernán Ramírez Necochea o Alfredo Jocelyn-Holt, entre otros.

Antonio Dougnac Rodríguez. Manual de Historia de Derecho Indiano, pp. 144 y ss.

A modo de ejemplo, la situación del país durante la década de 1970, en lo que se refiere a atribuciones de la Contraloria,

tribunales de justicia y Parlamento. Anteriormente la crisis institucional de los años 1924 y 1925, así como el primer gobierno de Carlos Ibáñez del Campo. Situación similar aunque marcada por una violencía extrema fue la de 1891, que historiadores como Encina la llaman "la dictadura de Godoy". 
flicto es parte esencial de la vida humana y ello lleva a que todo grupo busque algún modo de solución de conflictos. Ontológicamente, la sentencia precede a la ley y a otras fuentes del derecho que importan normas de carácter general. El juez es una de las figuras que está presente en todo pueblo.

Sin embargo, la evolución institucional del poder judicial en Chile no ha sido aún objeto de un estudio acabado a diferencia de lo que ocurre con el presidente de la república, ejército, el cabildo, la iglesia o el congreso nacional ${ }^{4}$.

Una explicación de esto se puede buscar en nuestra idiosincrasia, que establece que el órgano legislador es el que determina lo que es justo ${ }^{5}$, lo que se ve exacerbado por el hecho de que en nuestra tradición jurídica tiene enorme relevancia la interpretación de la ley de acuerdo a los postulados de la escuela de la exégesis y que, por lo tanto, se considera al juez como la boca de la ley. Es común escuchar en los medios de comunicación a personas legas exigir que los tribunales apliquen la ley y prescindan de sus concepciones personales.

También se puede explicar lo anterior por la poca importancia asignada a la doctrina como medio para transformar instituciones y fijar el sentido de las normas. En este contexto el poder judicial debe estar vinculado con las escuelas de derecho. Es labor de éstas, mediante el debate y la crítica, contribuir al cambio de la jurisprudencia y desarrollar la dogmática de los derechos fundamentales.

Todo esto además encuentra una explicación en el concepto de Estado heredado del iluminismo. El estado debe llevar la felicidad al pueblo, aún contra su propia voluntad. Esta concepción paternalista exalta las funciones administrativas y legislativas. El parlamento es entendido como el órgano que concentra la participación de la ciudadanía. Los lugares que simbolizan las disputas políticas y las reivindicaciones de todo tipo son el palacio de gobierno y el edificio del congreso, en detrimento de otros canales de participación.

Ello hace que se entienda que los tribunales son meros órganos operadores del sistema. La dimensión jurídica de esta concepción se refleja en la codificación y el constitucionalismo decimonónico que establece que sólo el legislador interpreta la constitución y la fuerza vinculante de esta la determina este al momento de dictar las leyes complementarias. La constitución es una declaración ideológica que, a diferencia de lo que ocurre en los albores del siglo XXI, no tiene fuerza vinculante directa. Esta situación en materia judicial es reconocida expresamente por la doctrina hacia el año 1900 en una de las principales obras interpretativas de la ley de organización y atribuciones de los tribunales. Ella es dictada en virtud de un mandato que establece el art. 105 de la constitución de $1833^{6}$. El sistema jurídico no necesariamente es transformado mediante una interpretación conforme a la constitución 7 .

También es propio del constitucionalismo acabar con el arbitrio judicial. El juez no puede ni debe fallar de acuerdo a la equidad salvo en los casos en que la ley expresamente lo autori-

\footnotetext{
Bernardino Bravo Lira. "Los estudios sobre la judicatura chilena en los siglos XIX y XX". Revista de Derecho Público, año 1976, pp. 89-116.

Muestra de esto es el título preliminar del C.C., al establecer una prelación entre las fuentes del derecho.

Carlos Risopatrón. "Ley de organización y atribuciones de los tribunales de Chile y comentarios ordenados con el objeto de hacer más fácil su estudio”,p. 14.

7 Prueba de esto es la existencia de normas del C.C. que se consideraron atentatorias respecto a derechos constitucionales. Así lo estima Rafael Valentín Valdivieso. Esto aparece en la recopilación dé sus escritos hecha por José Ramón Astorga. Obras Cientificas $y$ Literarias, Tomo II, pp. 7-58.
} 
$\mathrm{za}^{8}$. El no puede modificar las penas, por muy draconianas que estas sean. Lo que se conoce como epiqueya debe ser suprimido. Muestra de esto es una de las interpretaciones de carácter histórico que se le puede dar al art. 23 del C.C.

A pesar de todo esto no hay explicación valedera a la hora de justificar este vacío. El presente trabajo no pretende abarcar toda la historia del poder judicial chileno sino sólo las características de éste al finalizar la época indiana y los ensayos constitucionales del primer tercio del siglo XIX.

\section{Antecedentes indianos}

Dentro de la tradición hispana, el rey castellano durante la Alta Edad Media jamás cedió del todo la facultad de administrar justicia y él conocía de los casos de corte y la segunda instancia. Hasta el siglo XVII se entiende que una de las funciones principales del juez es mantener al pueblo en paz y justicia y ello se busca simbolizar en elementos de la naturaleza que reúnan la tierra, el cielo y lo que está bajo la tierra como lo es el árbol. ${ }^{9}$ Esta función recibe consagración expresa en las partidas ${ }^{10} \mathrm{y}$ de esta manera pasó a América, en la que mediante una ficción se entiende que la Real Audiencia en su conjunto es la representante del monarca y debe ser tratada de alteza. Ella a Chile llega el año 1565, a la ciudad de Concepción - a esa época de mucha mayor preponderancia que Santiago-, y tuvo una efimera existencia ya que se extingue en 1575. Vuelve a fundarse, esta vez en la ciudad de Santiago el año 1609. Será el tribunal que encarnará la vida jurídica por más de doscientos años y su supresión marcará el cambio de época histórica.

El máximo tribunal de este territorio no sólo cumple funciones jurisdiccionales sino también de carácter político. Los oidores son personas de reconocida erudición y por ende constituyen un cuerpo consultivo al que en diversas ocasiones recurre el gobernador o el virrey. El sistema jurídico indiano contempla un reconocimiento institucional al autoritas. Son órganos creadores de derecho no sólo a través de autos acordados y sentencias sino también mediante una forma especial que reviste la ley indiana llamada Real Provisión ${ }^{11}$.

El presidente de la Real Audiencia era el gobernador. Esta figura concentraba, además de estos cargos, los de capitán general, superintendente de hacienda y vicepatrono de la Iglesia.

Acumula todo tipo de facultades y ejerce jurisdicciones privativas y excluyentes de la ordinaria en lo que dice relación con los ramos de gobierno. El gobernador tiene competencia privativa en materia tributaria y, en su carácter de capitán general, la tiene también en lo que dice relación con la justicia militar ${ }^{12}$.

8 Para mayor información, véase Ítalo Merello Arecco, en "Ley mariana de fundamentación de sentencias frente a la clemencia judicial en materia penal”. En: Revista de Estudios Histórico-Jurídicos, año 1983, pp. 71-98.

9 Manuel García Pelayo. El concepto medicval de derecho.

10 Partidas 2,13,1.

11 Antonio Dougnac Rodríguez. Op. cit., pp. 97-119.

12 Luis Méndez Calzada. "La función judicial en las primeras épocas de la independencia. Estudio sobre la formación evolutiva del poder judicial argentino". Buenos Aires. Editorial Losada 1944. 
El gobernador, como presidente de la Real Audiencia, debía intervenir en las facultades económicas del tribunal, en el nombramiento de auxiliares en la administración de justicia como escribanos, relatores y otros. Además, como presidente de la Real Audiencia ejerce la potestad disciplinaria de corregidores y alcaldes mayores así como también es tribunal unipersonal al momento de determinar la responsabilidad ministerial de los oidores. Conoce en primera instancia de los delitos comunes en que estos participan.

En su calidad de gobernador, le corresponde resolver contiendas de competencia entre la gobernación y la Real Audiencia.

La jurisdicción ordinaria no es universal, y dentro de su competencia están los delitos comunes y causas de derecho privado, de las cuales se excluyen las mercantiles, pues aquellos eran conocidos por un juez diputado del consulado de Lima primero, y por el tribunal del consulado con asiento en Santiago después (1795).

Situación similar ocurrió al fundar el tribunal de minería. Ambos reflejan la importancia que la política de la corona asigna a los gremios. Se estimó que por la especialidad de ambas actividades económicas lo mejor sería un tribunal paritario y especializado.

El Real Tribunal de Minería apenas sobrevivió unos años a la liberalización del gobierno, en tanto el consulado tuvo una vida bastante larga. Este tribunal desapareció con la dictación de la ley de organización de los tribunales del año $1876^{13}$.

Las nuevas ideas estimaron que atentaba contra la igualdad y la libertad. Las causas mineras pasarían a la jurisdicción ordinaria en la década de 1820. Lo mismo ocurriría con los pleitos en materia mercantil después de la dictación de la ley de organización de los tribunales.

Pero todo lo anterior no significaba que el poder estaba concentrado de manera absoluta. La formación de un poder judicial independiente y letrado fue producto del reformismo borbónico. Desde un principio se buscó para la Real Audiencia sólo jueces letrados y que ésta fuese un órgano que ejerciese un control político sobre el gobernador. En la medida en que se centraliza la administración la corona procura resguardar la independencia de los tribunales.

En este sentido marca un hito la instrucción de regentes de 1776. Esta separa al gobernador de la Real Audiencia, manteniendo su título de presidente de ésta. El regente se hace cargo de todas las facultades económicas y tiene la obligación de visitar una vez por semana la cárcel para saber quiénes están presos por orden o abuso del gobernador. Su función era tutelar la libertad ambulatoria de todos, no importando en virtud de qué jurisdicción el súbdito había sido privado de libertad. La instrucción de regentes también establece para éste la obligación de resguardar el derecho de acción de todas las personas para recurrir ante el máximo tribunal por actos de gobierno. Aquí está la consagración del control jurisdiccional de los actos de gobierno. El regente, de acuerdo a la disposición XLI de la instrucción, tenía para estos casos imperio "...el hacer que tengan puntualísimo cumplimiento, zelando que no defrauden unas decisiones tan justas y apartando qualesquier motivo de terror..."

El sistema de frenos y contrapesos tuvo por principal representante a la Real Audiencia. Este tribunal era integrado por oidores en número de cuatro y que también actuaban como alcaldes del crimen, por un fiscal, por un alguacil mayor, por un teniente de gran chanciller y ministros que fuesen necesarios.

13 Copia de la instrucción de regentes se encuentra en Revista Chilena de Historia del Derecho, Nº 3, año 1964, pp. 57 a 69. 
A fin de resguardar la independencia y asegurar la imparcialidad todos los integrantes eran bien pagados y se les sometía a una serie de prohibiciones de carácter muy reglamentario, como por ejemplo no realizar visitas sociales o no comprar bienes inmuebles.

Hacia el año 1776 hubo dos fiscalías: una civil y otra criminal. La función de ellas era velar por los intereses comunes.

Además de las funciones ya señaladas éste era el tribunal de segunda instancia, conociendo además el recurso de suplicación contra sentencias dictadas por él mismo, conocía el recurso de nulidad y pleitos de personales que tienen fuero y conocía recursos de fuerza (jurisdicción eclesiástica).

Por último, cabe agregar que la Real Audiencia fue disuelta en 1811 después del motín de Figueroa, acusando a sus miembros de instigadores del mismo y por ello fueron destituidos. Volvió a nacer durante la restauración absolutista pata extinguirse finalmente en 1817.

Este hecho debe ser destacado porque es la única vez en nuestra historia que un tribunal superior está en receso por tanto tiempo y, si bien las autoridades de ese momento establecieron otros tribunales superiores, ni antes ni después una crisis institucional implicó que se removiese a todos los miembros de máximo tribunal. Las posteriores crisis institucionales nunca llegaron a extremo de remover a todos los jueces del máximo tribunal. Las crisis institucionales propias de la vida republicana sólo excepcionalmente removieron a miembros de la corte suprema. Durante la guerra civil de 1891, la Corte Suprema fue cerrada; pero ello duró sólo unos meses, ya que al finalizar el conflicto todos los ministros fueron reintegrados en sus cargos; por lo tanto, este receso fue temporal y no opacó mayormente la continuidad de este tribunal. Ello sí ocurrió con los integrantes de tribunales de inferior jerarquía.

La crisis institucional de la década de 1810 es la de mayor magnitud que ha afectado a la judicatura de Chile, además porque no hubo grandes cambios en el sistema jurídico ni tampoco en la legislación vigente. Los únicos cambios de trascendencia ocurrieron en el área del derecho constitucional y los cambios en esta rama del derecho no tenían la importancia que tiene hoy día por las razones antes esgrimidas. Algunos de los textos constitucionales dictados en esta etapa contemplan tribunales superiores cuyo único fin es suplir la ausencia del Consejo de Indias, pues es una premisa adoptada ya en el reglamento constitucional de 1812 que una de las bases del ejercicio de la jurisdicción es la territorialidad.

A partir de 1817 bastaron sólo siete años para que fuese reemplazado por otro tribunal de igual categoría como es la Corte Suprema, creada en 1824. La gran diferencia entre ésta y la Real Audiencia es que la primera representa a la república y la segunda al monarca.

Entre las críticas que se pueden hacer al sistema judicial indiano está la falta de seguridad jurídica debida a la existencia del arbitrio judicial; la no fundamentación de las sentencias a partir de la real cédula de Carlos III de 23 de junio de 1768; la inexistencia de una sistematización del derecho vigente; el anacronismo de muchas de sus normas, y la falta de publicidad de las mismas, ya que los bandos eran dictados de manera muy excepcional.

Sin embargo, muchos de estos vicios no se subsanaron con el advenimiento de la república. Es más, consta que dos autos acordados dictados en el siglo XVIII se encuentran vigentes hasta la dictación del código de procedimiento penal ${ }^{14}$.

14 Alberto Coo Tagle. Concordancias de la lei de organización i atribuciones de los tribunales, pp. 507-513. 
El primero de ellos dice relación con la sustanciación de las causas criminales y fue dictado el 25 de agosto de 1757 . Su autor es el doctor José Perfecto de Salas ${ }^{15}$ y entre sus principales características se puede anotar que consagra, a favor del imputado, un derecho a la defensa letrada, ciertos trámites especiales en caso que el acusado sea un indio; establece también que la primera resolución del procedimiento será un auto" cabeza de proceso"y establece la obligación de contar con la asesoría de un abogado para dictar la sentencia (sobre todo si se trata de lugares aislados del resto del reino); y también contempla la existencia del querellante como parte activa del procedimiento.

El segundo auto acordado data del 29 de mayo de 1797 y dice relación con la prueba testimonial. Prohíbe expresamente que acusante y acusado usen los mismos testigos y esta norma tuvo su razón de ser en el combate de una práctica que estaba provocando una administración torcida de la justicia.

Por último, debe tenerse en cuenta que los vicios heredados del sistema jurídico indiano, así como los auto acordados recién mencionados, sólo dejaron de tener vigencia con la dictación de los códigos procesales, casi un siglo después.

\section{III. Época republicana ${ }^{16}$}

Antes de proceder a un análisis pormenorizado de cada uno de los textos dictados por el constituyente, debe tenerse presente que la separación de funciones entre los clásicos tres poderes fue de desarrollo paulatino, debido a la experiencia en la aplicación de cada uno de ellos y esto se refleja en que los provenientes de la Patria Vieja confunden reiteradamente las funciones de cada cuerpo y la redacción de éstos es equívoca. No obstante, se aprecia un desarrollo progresivo entre cada uno de ellos.

A diferencia del estudio de la época anterior, en ésta deben conjugarse aspectos orgánicos y dogmáticos, ya que ciertos derechos sólo pueden ser cautelados por el poder judicial.

El reglamento provisional de la junta gubernamental del 5 de diciembre de 1810 concentra en ésta facultades de todo tipo. Establece que las causas civiles entre partes serán de competencia de los juzgados ordinarios y que "la junta resolverá por sí misma todas las causas en que tengan interés el fisco y los que pertenezcan a la administración pública”. Ello ya implica la supresión de la facultad de la Real Audiencia para revisar actos de gobierno y confunde facultades judiciales y administrativas. Estamos ante un órgano que en estos casos es juez y parte. La Junta pasa a ser tribunal de segunda instancia en lo que respecta a recursos de suplicación y se establece como tribunal el Supremo Consejo de la nación. Si bien el mismo texto reconoce su provisionalidad, no es menos cierto que al momento de analizarlo de acuerdo a lo que fue el constitucionalismo clásico es claramente un texto que no lo representa, y respecto a la política borbónica es un retroceso, ya que contradice su planteamiento de independencia del poder judicial. 
Avala esta tesis el preámbulo del "reglamento para el arreglo de la autoridad ejecutiva provisoria de Chile", dictado el 14 de agosto de 1811. En éste el Congreso manifiesta su interés de desprenderse de las facultades jurisdiccionales y señala que su ideario es lograr la división entre los tres poderes del estado, buscando definir las atribuciones de cada uno. Para ello instala un tribunal colegiado llamado "Autoridad ejecutiva provisoria de Chile". Debe considerarse que en este momento la Real Audiencia ha dejado de existir.

El tenor literal de este cuerpo es confuso ya que para referirse a este órgano emplea las expresiones poder ejecutivo, autoridad ejecutiva o poder ejecutivo provisorio. El órgano principal es el congreso y este representa la voluntad soberana. La autoridad ejecutiva provisoria, de acuerdo al art. 5 , tiene imperio respecto de tropas y milicias ordinarias dentro de su partido. El reglamento conserva las jurisdicciones especiales en materia tributaria y de justicia militar. En lo que respecta a recusación de sus miembros se remite a las reglas establecidas para este incidente en la regulación dictada para oidores de la Real Audiencia. De acuerdo al art. 17 se mantienen las reglas protocolares que regían a la Real Audiencia, pero en vez de que en conjunto se la trate de alteza ahora se la trata de excelencia.

El reglamento constitucional de 1812 establece la independencia de la judicatura y manda a velar por el cumplimiento de las leyes al gobierno. Consagra el principio del debido proceso y la sentencia conforme a derecho.

Se autoriza la detención sólo si existe una prueba que demuestre la participación del detenido en algún ilícito. Este reglamento menciona la existencia de tribunales de apelaciones con ocasión del juicio de residencia para los vocales de la junta.

El art. 16 de este reglamento establece que sólo se pueden examinar cosas y lugares o aprehender personas si hay una orden acompañada de juramento judicial.

Este es el primer documento emanado del constituyente que consagra derechos fundamentales. Es el primero que muestra una parte orgánica y una parte dogmática.

Este ordenamiento quedó sin efecto por el recrudecimiento de la guerra, que llegó a consagrar un estado de excepción, sancionado por el reglamento para el gobierno provisorio de 1814. Este consagra por vez primera y única en la PatriaVieja un poder ejecutivo unipersonal.

En éste, la única mención a la judicatura se hace a raíz del juicio de residencia hecho al Director Supremo. Se establece que éste lo realizará un juez elegido por el Congreso si éste está convocado o próximo a convocarse o, en caso contrario, por las corporaciones.

Como resumen de los ensayos del poder constituyente en la primera etapa del proceso emancipador se puede concluir que la judicatura es mencionada en gran parte de ellos y que la configuración paulatina de la división entre los tres clásicos poderes del estado fue un ideario que se fue consolidando debido a la experiencia, no obstante ser en líneas generales poco consistentes con las doctrinas de derecho público en boga en aquella época.

La judicatura ocupó un papel importante y en casi todos los textos es mencionada; pero, a excepción del reglamento de 1812, no se pueden encontrar indicios de un desarrollo dogmático de ésta.

La constitución de 1818 es una constitución extensa en que ya aparecen claramente diferenciadas la parte orgánica y la parte dogmática.

En lo que respecta a los derechos del hombre se establece que la seguridad individual es un derecho inajenable. Se consagra el principio de debido proceso y la presunción de inocen- 
cia. Se consagra como garantía constitucional la medida cautelar de fianza. El capítulo primero del título primero de esta constitución pone especial énfasis en la recepción de las ideas liberales en lo que respecta a la aplicación del derecho penal y restringe las penas corporales; no obstante, no hay consagración expresa del principio pro reo.

La constitución de 1818 consagra como principio derivado de la separación de los poderes la inavocabilidad de las contiendas conocidas por los tribunales de justicia.

En lo que respecta a la facultad de imperio no contempla norma de carácter general, pero sí una especial en el art. 20 del capítulo primero del título cuarto en la que se establece que las sentencias contra el fisco no serán ejecutadas sin mandato expreso del director. El art. 22 del mimo capítulo consagra la facultad del director supremo de indultar a los condenados a pena capital.

Consagra un título completo a la autoridad judicial y señala que ésta reside en el supremo tribunal judiciario y en todos los juzgados subalternos a éste. Una particularidad de este título es que establece cuál será la legislación aplicable por los tribunales para resolver los conflictos que lleguen a su conocimiento y éstas serán "...las leyes, cédulas y pragmáticas que hasta aquí han regido, a excepción de las que pugnan con el actual sistema liberal de gobierno..." 17.

Al regular el supremo tribunal judiciario establece que tendrá competencia privativa para conocer los recursos de segunda suplicación. En el sistema indiano los recursos de segunda suplicación eran conocidos por el consejo de indias. Concordando esto con la frase transcrita en el acápite anterior se aprecia que este tribunal tiene por objeto suplir la ausencia del máximo tribunal del sistema indiano, porque el derecho procesal y el sistema de recursos no ha cambiado.

En el capítulo dedicado al supremo tribunal judiciario también se reconoce la existencia de tribunales de hacienda, y de alzada de minería y consulado. Ambas jurisdicciones aún se mantienen, lo que lleva a concluir que la constitución de 1818 no implica modificación alguna en el derecho procesal orgánico ni tampoco en el derecho procesal funcional heredado de la restauración absolutista.

Esta constitución también determina la manera en que se compondrá el supremo tribunal. Establece un sistema de designación mixta en que elige el Director Supremo a base de una terna propuesta por este tribunal. No consagra la manera en que se designarán los miembros de los otros tribunales.

En el capítulo tercero del mismo título se consagra una cámara de apelaciones en la que se conserva el cargo de regente. Este capítulo cae en una regulación de carácter reglamentaria y, entre otras innovaciones respecto a los textos constitucionales anteriores, está la de establecer un trámite ante la cámara antes de ejecutarse penas establecidas por jueces ordinarios en causas criminales si la pena es aflictiva o de muerte. No se consagra esto como un recurso sino como un trámite de aprobación. Otra innovación de este texto es establecer un mandato al legislador para crear tribunales cuyo objeto sea reducir las contiendas a transacciones o compromisos extra judiciales.

La constitución de 1822 establece que el gobierno de Chile estará compuesto de tres poderes independientes y que el judicial residirá en los tribunales de justicia. Establece un

17 Art. 2, capítulo primero, título V. 
tribunal supremo de justicia que tendrá el carácter de tribunal superior, descendiendo en el orden jerárquico estará la cámara de apelaciones y, por último, los tribunales ordinarios. Una diferencia con la constitución anterior es que ésta establece que el presidente del tribunal supremo será designado por el poder ejecutivo y la designación de los que ocuparán las vacantes de este tribunal será a base de un procedimiento en que intervendrán los tres poderes. Habrá una terna propuesta por el supremo tribunal y el ejecutivo y el legislativo elegirán al reemplazante de común acuerdo.

Este tribunal conoce recursos de segunda suplicación, juicios de residencia, entre otras. Las recién mencionadas muestran una vez más la pervivencia del derecho indiano en esta primera época y la posible equiparación entre el tribunal supremo y el consejo de indias.

$\mathrm{Al}$ igual que la constitución anterior, en toda sentencia que entraña una pena de muerte y además las que significan expatriación o destierro se establece la obligación de realizar el trámite de aprobación por este tribunal.

Al regular la cámara de apelaciones establece que dentro de ésta estará la junta superior contenciosa de hacienda y consagra expresamente la facultad disciplinaria respecto de los tribunales inferiores.

A diferencia de la constitución anterior, en ésta el constituyente regula la institución de los jueces de paz -la constitución de 1818 establecía respecto a este instituto un mandato para el legislador- manteniendo la finalidad de conciliar y componer a los litigantes.

Por último el constituyente estableció un capítulo especial que regula la relación entre la administración de justicia y los derechos individuales. En éste se consagra por vez primera en nuestro ordenamiento constitucional la imposibilidad de ser juzgado por comisiones especiales. Se establece una acción pública contra el juez que ha incurrido en soborno, cohecho o prevaricación.

En lo que respecta a las garantías del reo, es una constitución que recoge las ideas más liberales de la época al establecer el principio de última ratio del derecho penal, de la proporcionalidad del delito y la concepción de la pena tiene un carácter preventivo especial y general y no de carácter retributivo.

Asimismo se establece que toda sentencia debe ser motivada. Esto en su momento fue considerado como una necesidad y un derecho, ya que el arbitrio judicial se había convertido en una práctica contra legem que será regulada por diversos cuerpos legales durante la primera mitad del siglo XIX ${ }^{18}$.

La constitución de 1823 no tuvo aplicación por ser en extremo confusa y confundir el derecho con la moral. En líneas generales, para los efectos de este trabajo se entiende que continúa con lo establecido por el constituyente en las dos constituciones inmediatamente anteriores.

Entre sus peculiaridades se encuentra que cambia la división en capítulos y títulos por una en que solamente establece títulos. El título referido al poder judicial es el que consagra los derechos fundamentales y establece que estos son protegidos por el poder judicial. Consagra el principio del debido proceso; establece la detención solamente en los lugares habilitados y que ésta sólo puede ser por orden del juez. Consagra que solamente se puede ser juzgado por

18 Ítalo Marello Arecco. Op. cit. 
tribunales establecidos por la ley y consagra el principio de la doble instancia. La segunda instancia es la apelación.

El máximo tribunal es la suprema corte de justicia que conoce los juicios de residencias; pero ya no aparece mencionado el recurso de segunda suplicación.

Este tribunal tiene la superintendencia directiva, correctiva, económica y moral ministerial sobre los tribunales de la nación. Agrega que la designación de todos los jueces será a partir de una terna elaborada por este tribunal de la cual elegirá a uno de ellos el Director Supremo.

Consagra también la institución del Procurador General desconocida hasta ese momento y cuya función consiste en defender los intereses públicos.

Es la primera constitución que consagra la existencia de cortes de apelaciones.

También establece la existencia de los jueces de conciliación, que cumplirán el mismo rol que los jueces de paz.

Incorpora la regulación de juicios prácticos que es para todos aquellos casos en que se requieren conocimientos especiales y que tienen que ver antes de todo con deslindes de propiedades y regulación de aguas y minas.

El proyecto de constitución federal para el estado de Chile ${ }^{19}$, presentado al poder legislativo el 1 de diciembre de 1826, si bien nunca pasó de ser un mero proyecto, también se incorpora en el presente estudio por entregarle al poder judicial una mayor responsabilidad política que las cartas fundamentales anteriores y posteriores. De algún modo, es una ruptura frente a la tradición que finalmente se impuso en materia constitucional, en lo que respecta a la Corte Suprema. En su art. 11 establece que el "poder supremo se divide en legislativo, ejecutivo $\gamma$ judiciario: estos tres se ejercerán separadamente, sin que en ningún caso puedan reunirse". Ninguna constitución contempló un tenor literal tan enfático para señalar la división de los poderes. El capítulo XIII regula el poder judicial de la nación. Establece una corte suprema, cortes departamentales de justicia y juzgados departamentales.

Regula la competencia privativa de la Corte Suprema. Este órgano solucionaría las controversias entre las provincias; controlaría todos los contratos celebrados por el gobierno y sus agentes; regula la institución del pase regio; dirime contiendas de competencia entre tribunales y es tribunal de fuero. El hecho de entregar el pase regio, dada la enorme discusión que en ese momento ya se suscitaba acerca de las libertades religiosas y el estatuto jurídico de la Iglesia Católica, junto con su relación con el estado, ya demuestra una enorme responsabilidad política. Lo mismo cabe señalar respecto de la regulación de los contratos celebrados por el poder ejecutivo o el hecho de solucionar las controversias entre las provincias.

En materia de garantías es curioso que este proyecto no contempló un catálogo de derechos básicos. No contemplaba parte dogmática alguna. Solamente en las disposiciones generales aplicables al poder judicial consagra una concepción liberal del derecho penal.

No obstante, debe recordarse que este fue un proyecto. Mientras éste se discutía, en el legislativo se dictó un reglamento provisorio para el régimen de las provincias y, en lo que respecta a las normas reguladoras del poder judicial, este cuerpo legal se remite a las normas ya existentes que datan del año 1824.

19 Ramón Briceño. Derecho Público Chileno, pp. 442 y ss. 
Las constituciones de 1828 y 1833 son los pilares del derecho constitucional chileno. La primera fue, en líneas generales, algo más liberal que la segunda y las reformas constitucionales de 1871 y 1874 lo que hicieron fue volver al espíritu de la constitución de $1828^{20}$. Hasta el momento mismo de la promulgación y publicación de la constitución de 1833 se discutía si ésta era una reforma o simplemente una nueva constitución ${ }^{21}$. Primó la segunda postura sobre la base de que la constitución dictada por José Joaquín de Mora establecía en su art. 133 que al cabo de ocho años recién se citaría a una convención con el objeto exclusivo de reformar o adicionar esta constitución.

El derecho constitucional, al regular relaciones de carácter político entre los diversos sectores que componen la nación, no debe establecer cláusulas de este tipo. La constitución de 1828 no logró supeditar la política al estado de derecho, por la transgresión a las normas de designación de presidente y vicepresidente, primero, y porque ésta situación provocó una guerra civil ${ }^{22}$. Después de casi veinte años de conflictos políticos en que la guerra fue usada como el medio para solucionarlos, la opinión pública estaba cansada del abuso de la libertad. Se prefirió el orden, lo que era incompatible con la constitución de 1828. El derecho nunca logra abarcar ni dar molde definitivo a la realidad.

Sin embargo, lo anterior no impide ver en ambas constituciones continuidad en lo que se refiere al poder judicial, por lo que serán tratadas en forma conjunta en el presente trabajo. Los cambios que se aprecian entre la constitución de 1828 y la de 1833 dicen relación con las facultades conferidas al poder ejecutivo y al legislativo, así como también a la centralización en la toma de decisiones, consagrada en la de 1833, versus una mayor autonomía de las provincias unida a la creación de órganos democráticos con facultades decisorias dentro de las mismas (asamblea provincial).

Comparado con los textos constitucionales anteriores, en ninguna de las dos el poder judicial está muy desarrollado, así como tampoco los derechos fundamentales.

La de 1828 consagra expresamente la división de los poderes y en materia dogmática conserva una concepción liberal del derecho penal; la imposibilidad de que la ley creadora de tribunales pueda tener efecto retroactivo y el hecho de que sólo proceda la expropiación de bienes por medio de sentencia judicial.

Una de las peculiaridades de la constitución de 1828 es que ordena al congreso formar un tribunal de cinco personas y un fiscal a partir de una lista de veinticuatro para que conozcan como tribunal de primera instancia todos aquellos delitos cometidos por miembros del poder ejecutivo, legislativo y por la Corte Suprema y que no digan relación con la trangresión de normas de derecho público. Es la única constitución de nuestra tradición en la que se consagra un tribunal especial solamente para estos efectos.

La constitución de 1828 reconoce la existencia de la Corte Suprema, las cortes de apelaciones y de los juzgados de paz y de los de primera instancia. La de 1833 sólo reconoce la existencia de jueces de comercio y alcaldes ordinarios. No reconoce a la Corte Suprema, la

20 Mario Verdugo Marincovic. "Los principios del constitucionalismo clásico en los ordenamientos fundamentales de Chile". En: Revista de Derecho Público, año 1976. p. 139.

21 Jaime Eyzaguirre Gutiérrez. Historia de Chile, pp. 544-548.

22 Francisco Encina. Historia de Chile. Editorial Nascimento. 1948, pp. 403-553. 
superintendencia directiva, correccional y económica sobre todos los tribunales del país a diferencia de la de 1828. La de 1833 sólo establece que deberá existir un órgano que tenga tal superintendencia.

Desde un punto de vista orgánico la constitución de 1828 establece cuáles serán materias de competencia privativa de los juzgados de paz y de la Corte Suprema, lo que no ocurre en la constitución de 1833.

El desarrollo del poder judicial bajo el imperio de la constitución de 1833 se dio antes que nada por el desarrollo del legislador.

\section{Conclusiones}

1) La judicatura es una de las instituciones de mayor estabilidad y gravitancia en nuestro ordenamiento jurídico.

2) Los ensayos constitucionales le otorgaron especial importancia al Poder Judicial pero la constitución de 1833 tuvo poco desarrollo comparativo en este aspecto. El desarrollo del poder judicial se dio por obra del legislador.

3) Los estudios acerca de la evolución del poder judicial son pocos por diversos motivos explicitados más arriba.

4) El derecho procesal funcional en Chile ha sido de desarrollo lento, como lo demuestra la vigencia de una gran cantidad de disposiciones heredadas del derecho indiano, vigentes hasta muy entrada la república. 